\title{
PRIMARY CILIA IN CHONDROGENIC DIFFERENTIATION OF EQUINE BONE MARROW MESENCHYMAL STEM CELLS:
}

\section{ULTRASTRUCTURAL STUDY}

\section{Running title: CHONDROGENIC DIFFERNTIATION OF BM-MSCs}

\author{
Luesma $\mathrm{MJ}^{1,2}$, Cantarero $\mathrm{I}^{3,4}$, Ranera $\mathrm{B}^{2,5}$, Remacha $\mathrm{AR}^{2,5}$, Castiella $\mathrm{T}^{2,6}$, \\ Romero $A^{2,5}$, Martín $I^{2,5}$, Rodellar $C^{2,5}$, Junquera $C^{1,2}$ \\ ${ }^{1}$ Department of Human Anatomy and Histology. Faculty of Medicine. Zaragoza, Spain. \\ ${ }^{2}$ Aragon Health Sciences Institute. Spain. \\ ${ }^{3}$ Department of Cellular Biology, Physiology and Immunology. Faculty of Medicine.
} Córdoba, Spain.
${ }^{4}$ Maimonides Institute for Biomedical Research of Cordoba (IMIBIC), Spain.
${ }^{5}$ Laboratory of Biochemical Genetics (Lagenbio). Faculty of Veterinary. Zaragoza, Spain.
${ }^{6}$ Pathology department. “Lozano Blesa” University Clinical Hospital. Zaragoza, Spain.

Author responsible for correspondence:

Dr. MJ. Luesma.

Department of Human Anatomy and Histology.

Faculty of Medicine.

University of Zaragoza. Domingo Miral s/n 50009 Zaragoza.

Telephone: 34- 876554392.

E-mail: mjluesma@unizar.es 


\begin{abstract}
Locomotor system disorders in equine species, such as tendon lesions, osteoarthritis or ligament injuries, are some of the most frequent causes of dramatic reduction in horse performance. Traditional therapies are aimed at the inflammatory process and pain, but they do not regenerate normal tendon or ligament matrix and do not reduce re-injured rates. Mesenchymal stem cells have started to use as therapeutic option to repair these injured tissues. Most studies have focused on their isolation, in vitro culture and phenotyping. However, mesenchymal stem cell ultrastructure has been disregarded in the last years. We investigate the ultrastructural characteristics of these cells once differentiated into chondrocytes. Ultrastructural analysis was conducted on suspension cultures of differentiated chondrocytes from bone marrow mesenchymal stem cells by means of transmission electron microscopy. The morphological characteristics of these cells, their ability to produce the extracellular matrix and the presence of a single cilium, could be indicative of the mesenchymal cells differentiation into chondrocyte phenotype. This study provides essential data to evaluate the degree of suitable phenotypic stability, for these cells can be used with repair purposes.
\end{abstract}

Keywords primary cilium chondrocyte; chondrocyte ultrastructure; equine BMMSCs.

\title{
INTRODUCTION
}

Regenerative Medicine has emerged as a promising therapy for the treatment of damaged tissues and organs. Mesenchymal stem cells (MSCs) are a ubiquitous population of adult stem cells that have the potential to grow in culture and differentiate into many mature cell types of mesodermal and non-mesodermal origin, including 
cartilage [1]. Besides, MSCs present low alloreactivity [2] and immunosuppression capacity [3]. The use of MSCs in orthopedic practice has recently and rapidly acquired an important role. Therapies based on the use of MSCs for the treatment of acute injuries as well as chronic inflammatory disorders are gradually becoming clinical routine.

Friedenstein et al. described for the first time the population of bone marrow stromal cells able to adhere to the plastic culture substrate, giving rise to colonies of fibroblast-like (spindle-shaped morphology) proliferating elements [4]. Since then, MSCs have been subsequently isolated from different tissue sources just as Pascucci et al. summarize [5]: periosteum, trabecular bone, adipose tissue, synovium, skeletal muscle, spleen, lung, skin, blood vessels and fetal adnexa (umbilical cord blood, umbilical cord matrix, amniotic membrane) either in human medicine or in veterinary medicine including horse [6-15].

Adult bone marrow contains hematopoietic stem cells (HSCs) and mesenchymal stem cells (MSCs). Compared to HSCs, MSCs are rare in bone marrow, representing 1 in 100.000 nucleated cells [16]. Whereas HSCs are a well-characterized population of self-renewing cells that give rise to all mature blood cell lineages [17], BM-MSCs are less defined. The immunophenotype of HSCs is well established by the expression of the surface markers CD14, CD34 and CD45 [18]. However, a unique marker to identify and define BM-MSCs has not been reported yet, although CD29 and CD44 might represent robust candidates [19]. Therefore for the time of being, the isolation and characterization of BM-MSCs are based on the criteria determined by the International Society of Cellular Therapy (ISCT) [20].

As the immunophenotype of MSCs is not completely clarified across the species, tissue sources or methods of analysis [9] the MSC morphological study acquires a 
relevant importance. This study would include the ultrastructural characteristics of these cells once differentiated into mature lineages of mesenchymal tissues. Worth noting the presence of primary cilia which are immotile and slender microtubule-based organelles $(9+0)$ that usually exist in a single copy on the surface of different cell types including chondrocytes [21]. They are sensory cellular antennae that can co-ordinate different cellular signalling pathways [22] functioning as a unique cellular site for mechano- and chemo-sensation to regulate cellular processes during development and in tissue homeostasis [22-24].

There has been an interest in equine MSC therapy for more than 10 years, especially in the treatment of musculoskeletal disorders such as tendon or joint disease. These types of injuries produce dramatic reduction in horse performance, even causing competition retirement, as the return to the same level of activity is often compromised. Traditional therapies do not allow complete tissue healing and quite often animals do not regain competitiveness because they do not regenerate to the level of the original tissues and do not reduce re-injured rates [25]. In the last years, autologous MSCs have been used to treat equine musculoskeletal disorders. Tendon injuries [25, 26], femorotibial lesions (meniscal, cartilage or ligamentous) [27], and microfractured chondral defects [28] have been treated with autologous BM-MSC with positive outcomes of the treated animals recovering their previous level of sport activity [25].

There are widespread reports concerning the isolation and characterization of MSCs in horses [29-32], few reports concerning the BMMSCs fine structure among which highlight the work of Colter et al. [33], but no study in depth of the ultrastructural characteristics of these cells once differentiated into chondrocytes [34]. A thorough understanding of pellet culture of BM-MSCs' towards chondrocytes fine structure and the functional characteristics of different cell organelles will, undoubtedly, provide 
essential data to evaluate the degree of suitable phenotypic stability of these cells to be used in transplants with repair purposes.

\section{MATERIALS AND METHODS}

\section{Cell Isolation and expansion}

Bone marrow from two animals (aged 10 years old) was harvested from the sternum using a Jamshidi 11 gauge needle; biological sample was obtained with owner consent and according to local animal welfare regulations. The study was approved by the ethics committee of the University of Zaragoza. BM-MSCs were isolated as previously described [30, 31]. Briefly, mononuclear cells were isolated by density gradient centrifugation on Lymphoprep ${ }^{\mathrm{TM}}$. The cells were rinsed with PBS, counted, and plated at $1 \times 10^{6}$ nucleated cells $/ \mathrm{cm}^{2}$ in growth medium (DMEM Low Glucose, supplemented with $10 \%$ Foetal Bovine Serum, 1\% Glutamine and 1\% Streptomyin/Penecillin). BM-MSCs were cultured until reaching $80 \%$ of confluence then passaged once using Trypsin/EDTA and stored in liquid nitrogen. After thawing, the cells were expanded for one passage more. Then, the characterization of BM-MSC profile was examined as routine [30, 31] (data not shown) prior to chondrogenic induction.

\section{Chondrogenic Differentiation}

At passage two, 250.000 BM-MSCs were pelleted and place under chondrogenic induction in duplicates. Chondrogenic medium consisted of DEMEM high Glucose supplement with 10\% FBS, 10ng/mL TGF $\beta-3,40 \mu \mathrm{g} / \mathrm{mL}$ ITS + premix, $50 \mu \mathrm{g} / \mathrm{mL}$ ascorbate-2-phosphate and 0,1 $\mu \mathrm{M}$ dexamethasone. Chondrogenic differentiation was confirmed in one pellet after 21 days of induction as follows: it was washed twice with 
PBS, fixed in $10 \%$ formalin, dehydrated in increasing amount alcohols, imbedded in paraffin blocks and sectioned in $4 \mu \mathrm{m}$ sections. The sections were stained with Hematoxilin-Eosin and chondrogenic-specific Alcian Blue staining. For Hematoxylineosin staining procedure, paraffin sections were de-waxed and hydrated. The slides were stained in hematoxylin for 5 min and dipped in acid alcohol agitating for a second then washed in tap water for $5 \mathrm{~min}$. The slides were transferred to $1 \%$ aqueous eosin for $30 \mathrm{~s}$ and washed in running tap water for $1 \mathrm{~min}$. The slides were dehydrated and cleared in xylene. For Alcian Blue staining procedure, paraffin sections were de-waxed, hydrated and stained with Alcian Blue solution for 30 min (1\% Alcian Blue in 3\% acetic acid, $\mathrm{pH}$ 2.5) then the slides were washed in running water for 2 minutes, rinsed in distilled, dehydrated, cleared in xylene, and coverslips were applied. The cells were observed using an Olympus BX51 light microscope and an Olympus DP72 digital camera (Olympus Imaging Corporation, Tokyo, Japan).

\section{Transmission electron microscopy}

For transmission electron microscopy studies, the other pellet was fixed in 2,5\% glutaraldehyde and 2\% paraformaldehyde in phosphate buffer overnight at room temperature, washed in $0.1 \mathrm{M}$ phosphate buffer for $5 \mathrm{~min}$., post-fixed with $2 \%$ osmium, rinsed, dehydrated in graded acetones (30\%, 50\%, 70\% with 2\% uranyl acetate, $90 \%$, 100\%), cleared in propylene oxide and embedded in araldite (Durcupan, Fluka AG, Buchs SG, Switzerland).

Semi-thin sections $(1.5 \mu \mathrm{m})$ were cut with a diamond knife, stained lightly with 1\% toluidine blue and examined by light microscopy (Olympus BX51 microscope, Olympus Imaging Corporation, Tokyo, Japan). 
Later, ultrathin $(0.05 \mu \mathrm{m})$ sections were cut with a diamond knife, collected on Formvar coated single-slot grids, counterstained with $1 \%$ uranyl acetate and with Reynold's lead citrate for 10 min. and examined under a FEI Tecnai G2 Spirit TEM (Oregon, USA). The images were captured with Advanced Microscopy Techniques, using a Corp. Charge-Coupled Device (CCD from Danvers, MA, USA) imaging system.

\section{RESULTS}

\section{Differentiation essays}

Chondrogenic differentiation was induced in vitro using pellet culture technique. After 21 days of the chondrogenic differentiation, equine BM-MSCs cultured formed microspheres of $2.5 \mathrm{~mm}$ diameter. The cells appeared in individualized lacunae surrounded by a large extracellular matrix (Fig. 1A), rich in sulphated glycosaminoglycans that were evidenced using Alcian Blue staining (Fig. 1B).

\section{Ultrastructural study}

On transmission electron microscopy, the growth area had a gradient of cellular density that decreased from the outer zone inward (Fig. 1C). The cortical cells were characterized by an ovoid/elliptical or irregular morphology. They usually formed clusters and sent cytoplasmic prolongations contacting at least with one neighboring cell (Fig. 2A); they also emitted dendritic filopodia or small adhesion areas with close cells characterized by electron-dense membrane reinforcements (Fig. 2B).

In the inner zone cells had a rather elliptical appearance. These cells were isolated, surrounded by a fibrillar matrix of middle electron-density and showed one side flattened (Fig. 3A). Cells contained well-developed organelles. The cytoplasm showed a 
granular appearance due to the presence of free ribosomes. All cells had a prominent rough endoplasmic reticulum, often dilated to give rise to large dilated cisternae filled with an electron-clear content. Numerous mitochondria homogeneously distributed throughout the cytoplasm could be observed. The cells had lipid droplets and lysosomes in their cytoplasm. Lysosomes presented different functional activity and residual bodies with lipid residual lamellar structures; multivesicular bodies formed by a large vacuole containing intraluminal small vesicles (exosomes) could be observed (Fig. 3B).

The nuclei were pale, large and oval in shape usually located toward the convex side of the chondrocytes with deep indentations facing the flattened side. They presented a functionally active euchromatin and a narrow band of marginal heterochromatin. Nucleoli were prominent, and the fibrillar region could sometimes be distinguished from the granular region, indicative of an intense synthetic activity of the ribosomal subunits (Fig. 3C).

In close relation with the endoplasmic reticulum, numerous dictyosomes of a well-developed Golgi apparatus could be found; it was formed of flattered cisternae, surrounded by different sized vesicles with finely granular content (Fig. 3D). These vesicles fused to concentrate its content in regions close to the cell membrane, forming large vacuoles containing granular-fibrillar matrix (Fig. 4A). These vacuoles detached from cells releasing large amounts of granular material with fibrillar inclusions (Fig. 4B). Collagen fibers with characteristic cross striation could be observed being part of the extracellular matrix (Fig. 4C).

Of particular interest has been to demonstrate the presence of primary cilia usually protruding from the flattened side of the chondrocytic profile (Fig. 5A). Primary cilia were composed of a basal body from which a ciliary shaft or axoneme was originated. Alar sheets appeared to anchor the distal portion of the basal body to the plasma 
membrane, laterally pericentriolar electron-dense satellites were observed, from which microtubules originate radially. The second centriole of the diplosome was located below and perpendicular to the basal body. The primary cilium was generally associated with the vesicular components of the Golgi apparatus which provided the necessary molecules in the intraflagellar transport. The ciliary axoneme projected into the pericellular matrix, and was often deflected, running parallel to the cell surface. The plasma membrane contained numerous coated vesicles next to the axoneme, indicating an autocrine communication mediated by the primary cilium. In the apical region of the axoneme, electron-dense reinforcements between the plasma membrane and ciliary membrane were observed, as well as connections with extracellular matrix fibers (Fig. 5B).

\section{DISCUSSION}

Isolation, expansion and differentiation of BM-MSCs have important clinical implications as they represent an excellent source for regenerative medicine. MSCs are known to have a potential for cell therapy on different tissues. The use of BM-MSCs has focused on cartilage regeneration [35, 36] a tissue known for its limited intrinsic capacity of healing.

Most studies focused on the isolation and characterization of MSCs and there is a serious lack of research on their ultrastructural features including these cells once differentiated into chondrocytes. According to Pascucci et al. [5] stem cell and their derived tissue lineages stability in culture conditions, meaning the maintenance of basic morphological features ("stemness"), is one of the most debated issues regarding stem cells. In this study we describe the fine structure by transmission electron microscopy of BM-MSC derived chondrocytes after isolation and differentiation. 
The fine structure of the chondrocytes derived from BM-MSCs described in our results is coherent with the chondrocytic profile shown by Wilsman and Fletcher [37] who described them as elliptical cells with one side flattened, an indented nucleus located towards the convex side of the chondrocyte and the indentation facing the flattened side, a well-developed Golgi complex, rough endoplasmic reticulum, and occasional lipid droplets. The presence of multivesicular bodies containing exosomes is not mentioned. A cilium protruding from the flattened side of the chondrocyte was also described. The diameter of the ciliary shaft remained relatively constant throughout its length and terminated abruptly in a bluntly rounded end. At the junction of the basal body and the shaft the chondrocytic plasma membrane evaginated to envelop the tubules. They observed that the angles of emergence of the cilia included the entire range from $0^{\circ}$ to $90^{\circ}$.

The orientation and position of primary cilia confer a specific polarity that provides essential positional cues for tissue morphogenesis and maintenance [38]. Although chondrocytes do not have apical and basal polarity in the conventional sense of epithelial cell polarity, they show a clear orientation in the adult articular cartilage in three ways: (a) within the chondron, (b) with respect to the articular surface (and/or the tidemark) and, (c) in relation to the direction of mechanical loading [39]. Poole et al. [40] describe three patterns of ciliary projection in chick embryo sternal chondrocytes: (1) where the axoneme was fully extended into, and formed maximum contact with, the extracellular matrix, (2) where the axoneme was partially extended into the matrix with a range of bending deflections along the ciliary shaft and (3) where the primary cilium was reclined against the cell surface with minimal matrix contact. In the study, a correlation between the axoneme deflection and the biomechanical properties of the matrix is suggested. Biochemical forces could be the cause of ciliary bending. Our 
ultrastructural study showed group two as the most frequent. Almost all cells exhibited a deflected axoneme projected into the pericellular matrix, running parallel to the cell surface but embedded in a pericellular microenvironment of extracellular matrix as consequence of non-weight-bearing or pressure situations of the cultured cells. The results of this study support the hypothesis that the chondrocytic primary cilium is an integral element to the maintenance of cartilage structure.

The chondrocytic primary cilia have the molecular mechanism needed to act as mechanosensory organelles, they are oriented into the pericellular matrix environment and interact with collagen fibers via receptors as $\alpha 2, \alpha 3$ and $\beta 1$ integrins, and NG2 [21, 41]. Moreover, the chondrocyte purinergic mechanotransduction involves the release of ATP via connexin 43 hemichannels which decorates the primary cilium [42]. Among the signaling pathways that can be regulated by primary cilia, Hedgehog (Hh) is important for maintenance of postnatal cartilage. Components of Hh signaling such as Smo (Smoothened), Supressor of fused (Sufu), and Gli proteins are enriched in primary cilia; even it is suggested a strong correlation between up-regulation of Hh signaling and Osteoarthritis progression [43].

The basal body of the cilium is physiologically coupled to Golgi apparatus in chondrocytes, which implies that synthetic and secretory function of extracellular matrix components may be controlled in part by the cilium. All chondrocyte cilia examined showed the basic structural pattern of the diplosomal centrioles situated adjacent to the trans-Golgi apparatus; an axoneme projecting into the extracellular matrix whose features were described in results; internal vesiculated macromolecules and membrane coated pits; confirming the structural correlation between the functional properties of the extracellular matrix. Pool et al. [36] termed primary cilia as “cybernetic probes” transducing biomechanical and or physicochemical information 
from the extracellular matrix, communicating this information to the centrosome and Golgi apparatus, and regulating the cellular synthetic and secretory responses necessary to maintain a functionally effective extracellular matrix [44, 45]. A physical and chemical deficiency in the chondrocytic primary cilia results in skeletal and growth plate abnormalities due to improper extracellular matrix secretion [46, 47]. Thus the evidence strongly suggests a significant role of the primary cilium in basic chondrocytic functioning.

The morphological characteristics of these cells, their ability to produce the extracellular matrix and the presence of a single cilium, could be indicative of the mesenchymal cells differentiation into chondrocyte phenotype.

In summary, the current study presents that equine BM-MSC treated with an inductive chondrogenic medium reveled the characteristics of differentiated cells with an intense synthetic and metabolic activity perfectly compatible with chondrocyte phenotype, thus mesenchymal cell transformation toward a steady chondrocytic phenotype could be verified.

\section{CONCLUSIONS}

Mesenchymal stem cells obtained from sternal bone marrow of adult horses have the capacity to undergo chondrogenic differentiation and may provide a locally recruitable or transplantable autogenous cell source for articular cartilage repair.

Besides the obvious interest of our research in the clinic of equine athletes, racing horses represent an excellent animal model for human sport medicine [25, 48]. In fact horses represent high performance athletes considered models for human pathologies 
because of similarities in terms of structure and biomechanics since musculoskeletal disorders frequently occur in both species.

\section{COMPETING INTERESTS}

There are no competing interests

\section{FUNDING}

This study was supported by the University of Zaragoza, Spain (UZ2013_FIS-04)

\section{CONTRIBUTIONS}

The authors declare the following contributions to the conduct of the study: harvesting, isolation and culture of BM-MSCs (RB, RAR, MI, RC, RA), optical microscopy interpretation (CT), ultrastructural study (JC, LMJ, CI), drafting of manuscript (LMJ, JC), critical revision of the manuscript for important intellectual content (all authors) and final approval of the manuscript (all authors). LMJ (mjluesma@unizar.es) take responsibility for the integrity of the work as a whole.

\section{REFERENCES}

[1] Pittenger MF, Mackay AM, Beck SC, Jaiswal RK, Douglas R, Mosca JD, et al. Multilineage potential of adult human mesenchymal stem cells. Science. 1999;284:1437.

[2] Stoltz JF, Bensoussan D, Zhang L, Decot V, De Isla N, Li YP, et al. Stem cells and applications: a survey. Bio-medical materials and engineering. 2015;25:3-26.

[3] Ranera B, Antczak D, Miller D, Doroshenkova T, Ryan A, McIlwraith CW, et al. Donor-derived equine mesenchymal stem cells suppress proliferation of mismatched lymphocytes. Equine veterinary journal. 2015.

[4] Friedenstein AJ, Deriglasova UF, Kulagina NN, Panasuk AF, Rudakowa SF, Luria EA, et al. Precursors for fibroblasts in different populations of hematopoietic cells as detected by the in vitro colony assay method. Experimental hematology. 1974;2:83-92. 
[5] Pascucci L, Mercati F, Marini C, Ceccarelli P, Dall'Aglio C, Pedini V, et al. Ultrastructural morphology of equine adipose-derived mesenchymal stem cells. Histology and histopathology. 2010;25:1277-85.

[6] Covas DT, Siufi JL, Silva AR, Orellana MD. Isolation and culture of umbilical vein mesenchymal stem cells. Brazilian journal of medical and biological research $=$ Revista brasileira de pesquisas medicas e biologicas / Sociedade Brasileira de Biofisica [et al]. 2003;36:1179-83.

[7] Crigler L, Kazhanie A, Yoon TJ, Zakhari J, Anders J, Taylor B, et al. Isolation of a mesenchymal cell population from murine dermis that contains progenitors of multiple cell lineages. FASEB journal : official publication of the Federation of American Societies for Experimental Biology. 2007;21:2050-63.

[8] da Silva Meirelles L, Chagastelles PC, Nardi NB. Mesenchymal stem cells reside in virtually all post-natal organs and tissues. Journal of cell science. 2006;119:2204-13.

[9] de Mattos Carvalho A, Alves AL, Golim MA, Moroz A, Hussni CA, de Oliveira PG, et al. Isolation and immunophenotypic characterization of mesenchymal stem cells derived from equine species adipose tissue. Veterinary immunology and immunopathology. 2009.

[10] Van den Heuvel RL, Versele SR, Schoeters GE, Vanderborght OL. Stromal stem cells (CFU-f) in yolk sac, liver, spleen and bone marrow of pre- and postnatal mice. British journal of haematology. 1987;66:15-20.

[11] Yoshimura H, Muneta T, Nimura A, Yokoyama A, Koga H, Sekiya I. Comparison of rat mesenchymal stem cells derived from bone marrow, synovium, periosteum, adipose tissue, and muscle. Cell and tissue research. 2007;327:449-62.

[12] Zuk PA, Zhu M, Ashjian P, De Ugarte DA, Huang JI, Mizuno H, et al. Human adipose tissue is a source of multipotent stem cells. Molecular biology of the cell. 2002;13:4279-95.

[13] Zvaifler NJ, Marinova-Mutafchieva L, Adams G, Edwards CJ, Moss J, Burger JA, et al. Mesenchymal precursor cells in the blood of normal individuals. Arthritis Res. 2000;2:477-88.

[14] Lange-Consiglio A, Corradetti B, Bizzaro D, Magatti M, Ressel L, Tassan S, et al. Characterization and potential applications of progenitor-like cells isolated from horse amniotic membrane. Journal of tissue engineering and regenerative medicine. 2012;6:622-35.

[15] Lange-Consiglio A, Corradetti B, Meucci A, Perego R, Bizzaro D, Cremonesi F. Characteristics of equine mesenchymal stem cells derived from amnion and bone marrow: in vitro proliferative and multilineage potential assessment. Equine veterinary journal. 2013;45:737-44.

[16] Jurczyszyn A, Czepiel J, Gdula-Argasinska J, Perucki W, Skotnicki AB, Majka M. The Analysis of the Relationship between Multiple Myeloma Cells and Their Microenvironment. Journal of Cancer. 2015;6:160-8.

[17] Kondo M, Wagers AJ, Manz MG, Prohaska SS, Scherer DC, Beilhack GF, et al. Biology of hematopoietic stem cells and progenitors: implications for clinical application. Annual review of immunology. 2003;21:759-806. 
[18] Zhao Y, Glesne D, Huberman E. A human peripheral blood monocyte-derived subset acts as pluripotent stem cells. Proceedings of the National Academy of Sciences of the United States of America. 2003;100:2426-31.

[19] Ranera B, Barry F. A horse of a different color. Cytometry Part A : the journal of the International Society for Analytical Cytology. 2014;85:658-9.

[20] Dominici M, Le Blanc K, Mueller I, Slaper-Cortenbach I, Marini F, Krause D, et al. Minimal criteria for defining multipotent mesenchymal stromal cells. The International Society for Cellular Therapy position statement. Cytotherapy. 2006;8:3157.

[21] Muhammad H, Rais Y, Miosge N, Ornan EM. The primary cilium as a dual sensor of mechanochemical signals in chondrocytes. Cellular and molecular life sciences : CMLS. 2012;69:2101-7.

[22] Satir P, Christensen ST. Structure and function of mammalian cilia. Histochemistry and cell biology. 2008;129:687-93.

[23] Green JA, Mykytyn K. Neuronal ciliary signaling in homeostasis and disease. Cellular and molecular life sciences : CMLS. 2010;67:3287-97.

[24] Luesma MJ, Cantarero I, Castiella T, Soriano M, Garcia-Verdugo JM, Junquera C. Enteric neurons show a primary cilium. Journal of cellular and molecular medicine. 2013;17:147-53.

[25] Renzi S, Ricco S, Dotti S, Sesso L, Grolli S, Cornali M, et al. Autologous bone marrow mesenchymal stromal cells for regeneration of injured equine ligaments and tendons: a clinical report. Research in veterinary science. 2013;95:272-7.

[26] Smith RK, Werling NJ, Dakin SG, Alam R, Goodship AE, Dudhia J. Beneficial effects of autologous bone marrow-derived mesenchymal stem cells in naturally occurring tendinopathy. PloS one. 2013;8:e75697.

[27] Ferris DJ, Frisbie DD, Kisiday JD, McIlwraith CW, Hague BA, Major MD, et al. Clinical outcome after intra-articular administration of bone marrow derived mesenchymal stem cells in 33 horses with stifle injury. Veterinary surgery : VS. 2014;43:255-65.

[28] McIlwraith CW, Frisbie DD, Rodkey WG, Kisiday JD, Werpy NM, Kawcak CE, et al. Evaluation of intra-articular mesenchymal stem cells to augment healing of microfractured chondral defects. Arthroscopy : the journal of arthroscopic \& related surgery : official publication of the Arthroscopy Association of North America and the International Arthroscopy Association. 2011;27:1552-61.

[29] Colleoni S, Bottani E, Tessaro I, Mari G, Merlo B, Romagnoli N, et al. Isolation, growth and differentiation of equine mesenchymal stem cells: effect of donor, source, amount of tissue and supplementation with basic fibroblast growth factor. Veterinary research communications. 2009;33:811-21.

[30] Ranera B, Lyahyai J, Romero A, Vazquez FJ, Remacha AR, Bernal ML, et al. Immunophenotype and gene expression profiles of cell surface markers of mesenchymal stem cells derived from equine bone marrow and adipose tissue. Veterinary immunology and immunopathology. 2011;144:147-54.

[31] Ranera B, Remacha AR, Alvarez-Arguedas S, Castiella T, Vazquez FJ, Romero A, et al. Expansion under hypoxic conditions enhances the chondrogenic potential of 
equine bone marrow-derived mesenchymal stem cells. Veterinary journal. 2013;195:248-51.

[32] Vidal MA, Kilroy GE, Lopez MJ, Johnson JR, Moore RM, Gimble JM. Characterization of equine adipose tissue-derived stromal cells: adipogenic and osteogenic capacity and comparison with bone marrow-derived mesenchymal stromal cells. Veterinary surgery : VS. 2007;36:613-22.

[33] Colter DC, Sekiya I, Prockop DJ. Identification of a subpopulation of rapidly selfrenewing and multipotential adult stem cells in colonies of human marrow stromal cells. Proceedings of the National Academy of Sciences of the United States of America. 2001;98:7841-5.

[34] Fortier LA, Nixon AJ, Williams J, Cable CS. Isolation and chondrocytic differentiation of equine bone marrow-derived mesenchymal stem cells. American journal of veterinary research. 1998;59:1182-7.

[35] Arnhold SJ, Goletz I, Klein H, Stumpf G, Beluche LA, Rohde C, et al. Isolation and characterization of bone marrow-derived equine mesenchymal stem cells. American journal of veterinary research. 2007;68:1095-105.

[36] Jo CH, Lee YG, Shin WH, Kim H, Chai JW, Jeong EC, et al. Intra-articular injection of mesenchymal stem cells for the treatment of osteoarthritis of the knee: a proof-of-concept clinical trial. Stem cells. 2014;32:1254-66.

[37] Wislman NJ, Fletcher TF. Cilia of neonatal articular chondrocytes: incidence and morphology. The Anatomical record. 1978;190:871-89.

[38] Blacque OE, Cevik S, Kaplan OI. Intraflagellar transport: from molecular characterisation to mechanism. Frontiers in bioscience : a journal and virtual library. 2008;13:2633-52.

[39] McGlashan SR, Cluett EC, Jensen CG, Poole CA. Primary cilia in osteoarthritic chondrocytes: from chondrons to clusters. Developmental dynamics : an official publication of the American Association of Anatomists. 2008;237:2013-20.

[40] Poole CA, Zhang ZJ, Ross JM. The differential distribution of acetylated and detyrosinated alpha-tubulin in the microtubular cytoskeleton and primary cilia of hyaline cartilage chondrocytes. Journal of anatomy. 2001;199:393-405.

[41] McGlashan SR, Jensen CG, Poole CA. Localization of extracellular matrix receptors on the chondrocyte primary cilium. The journal of histochemistry and cytochemistry : official journal of the Histochemistry Society. 2006;54:1005-14.

[42] Knight MM, McGlashan SR, Garcia M, Jensen CG, Poole CA. Articular chondrocytes express connexin 43 hemichannels and P2 receptors - a putative mechanoreceptor complex involving the primary cilium? Journal of anatomy. 2009;214:275-83.

[43] Chang CF, Ramaswamy G, Serra R. Depletion of primary cilia in articular chondrocytes results in reduced Gli3 repressor to activator ratio, increased Hedgehog signaling, and symptoms of early osteoarthritis. Osteoarthritis and cartilage / OARS, Osteoarthritis Research Society. 2012;20:152-61.

[44] Poole CA, Flint MH, Beaumont BW. Analysis of the morphology and function of primary cilia in connective tissues: a cellular cybernetic probe? Cell motility. 1985;5:175-93. 
[45] Poole CA, Jensen CG, Snyder JA, Gray CG, Hermanutz VL, Wheatley DN. Confocal analysis of primary cilia structure and colocalization with the Golgi apparatus in chondrocytes and aortic smooth muscle cells. Cell biology international. 1997;21:483-94.

[46] Haycraft CJ, Zhang Q, Song B, Jackson WS, Detloff PJ, Serra R, et al. Intraflagellar transport is essential for endochondral bone formation. Development. 2007;134:307-16.

[47] Koyama E, Young B, Nagayama M, Shibukawa Y, Enomoto-Iwamoto M, Iwamoto $\mathrm{M}$, et al. Conditional Kif3a ablation causes abnormal hedgehog signaling topography, growth plate dysfunction, and excessive bone and cartilage formation during mouse skeletogenesis. Development. 2007;134:2159-69.

[48] Denoix JM. [The horse as an athlete: an animal model of choice for sports medicine: sonographic studies of joint disorders]. Bulletin de l'Academie nationale de medecine. 2008;192:521-36; discussion 36-40. 


\section{FIGURE LEGENDS}

Fig. 1. Chondrogenic differentiation (21 days). Pellet culture system. 1A. (HE) Cells appear in individualized lacunae. Magnification x40. 1B. (Alcian Blue staining) Large extracellular matrix rich in sulphated glycosaminglycans. Magnification x40. 1C. (EM) The growth area has a gradient of cellular density.

Fig 2. Cortical cells. 2A. Cells appear grouped, show ovoid or polygonal morphology and send cytoplasmic prolongations that contact with one or more neighboring cells (arrows). 2B Detail of 2A. Filopodia or small adhesion areas are identified by electrondense reinforcements in the membranes (arrows). $\mathrm{N}$ : nucleous.

Fig 3. Inner zone. 3A. Isolated oval cells surrounded by a fibrillar matrix. 3B. Cells contain abundant rough endoplasmic reticulum (er), mitochondria, lipid droplets (ld) and lysosomes (ly) in their cytoplasm. Lysosomes present different functional activity and lipidic residual lamellar structures myelin (asterisk); note the presence of multivesicular bodies (mvb). 3C. The nucleus shows functionally active euchromatin. The nucleolus is prominent and the fibrillar region can sometimes be distinguished from the granular region (arrows). 3D. Numerous dictyosomes of the Golgi apparatus can be found (G), finely granular content vesicles of varying sizes are released (V).

Fig. 4. Extracellular matrix formation (m). 4A. These vesicles fuse to concentrate its content in regions close to the cell membrane. 4B. These vacuoles detach from cells releasing large amounts of granular material with fibrillar inclusions. 4C. Collagen fibers with characteristic cross striation. 
Fig.5. Primay cilium and chondrocytes. 5A. The primay cilium is generally associated with the vesicular components of the Golgi. 5B Detail of 5A. The primary cilium originates from basal body (bb). The second centriole is observed near the bb (arrow). Note the electron-dense reinforcements between the plasma membrane and ciliary membrane in the apical region of the axoneme (dotted arrow) as well as connections with extracellular matrix fibers (arrowheads). Pinocytic vesicles (pv). Golgi (G). Microtubule (mt). Alar sheet: (s).

Figure 1

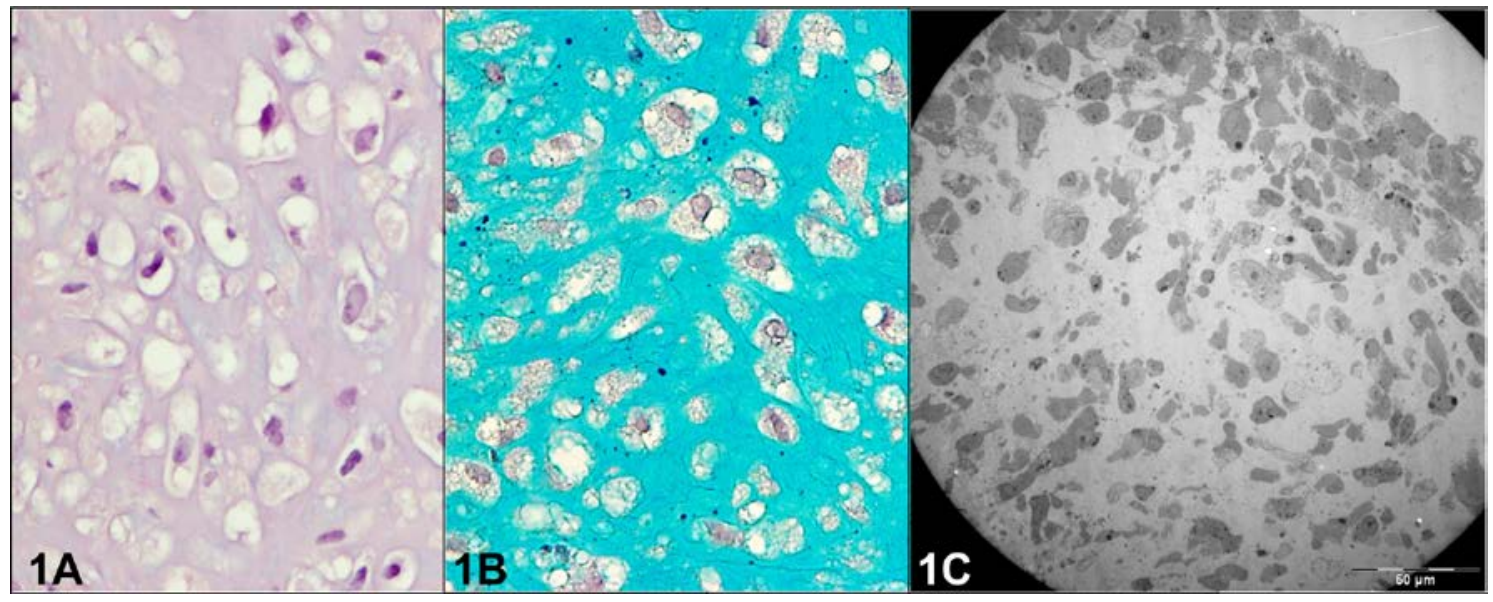

Figure 2
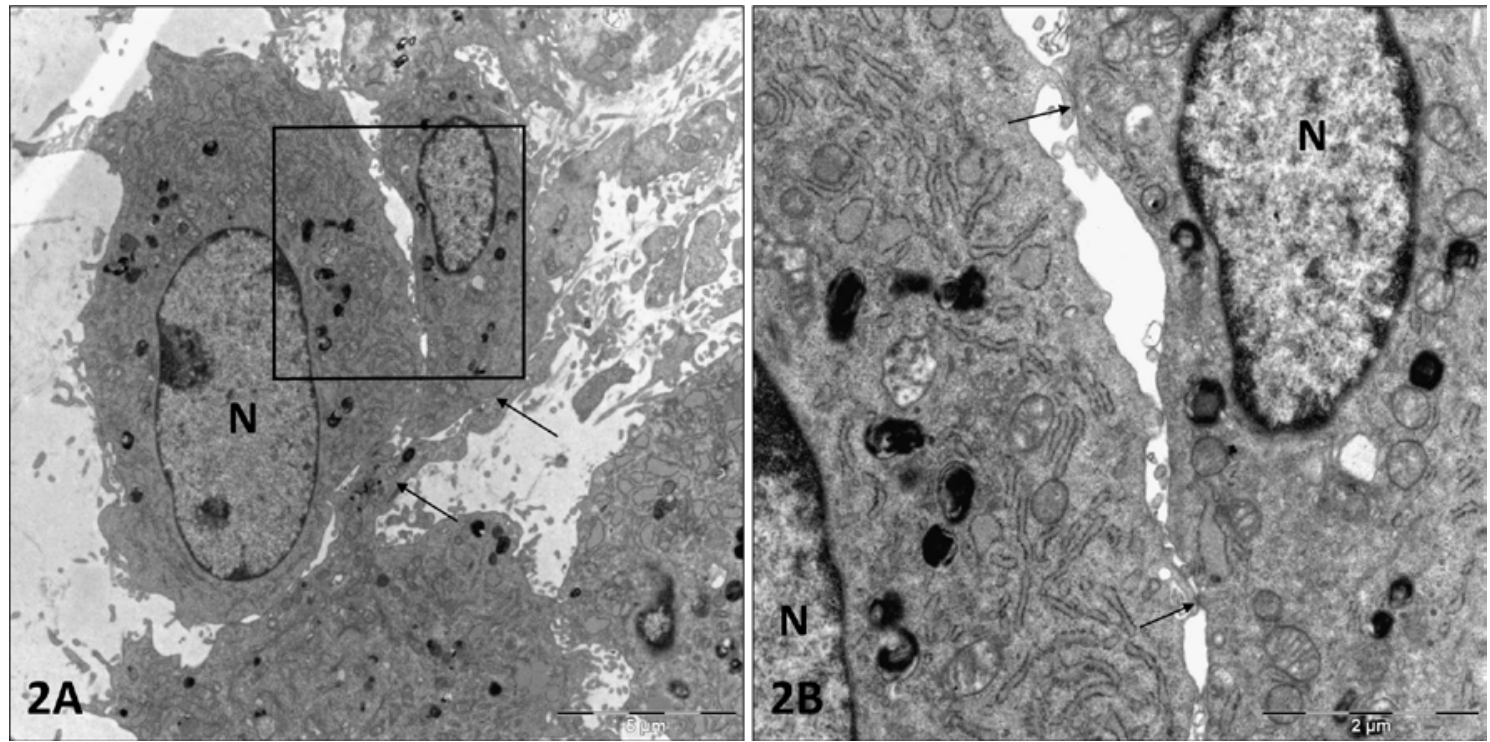
Figure 3
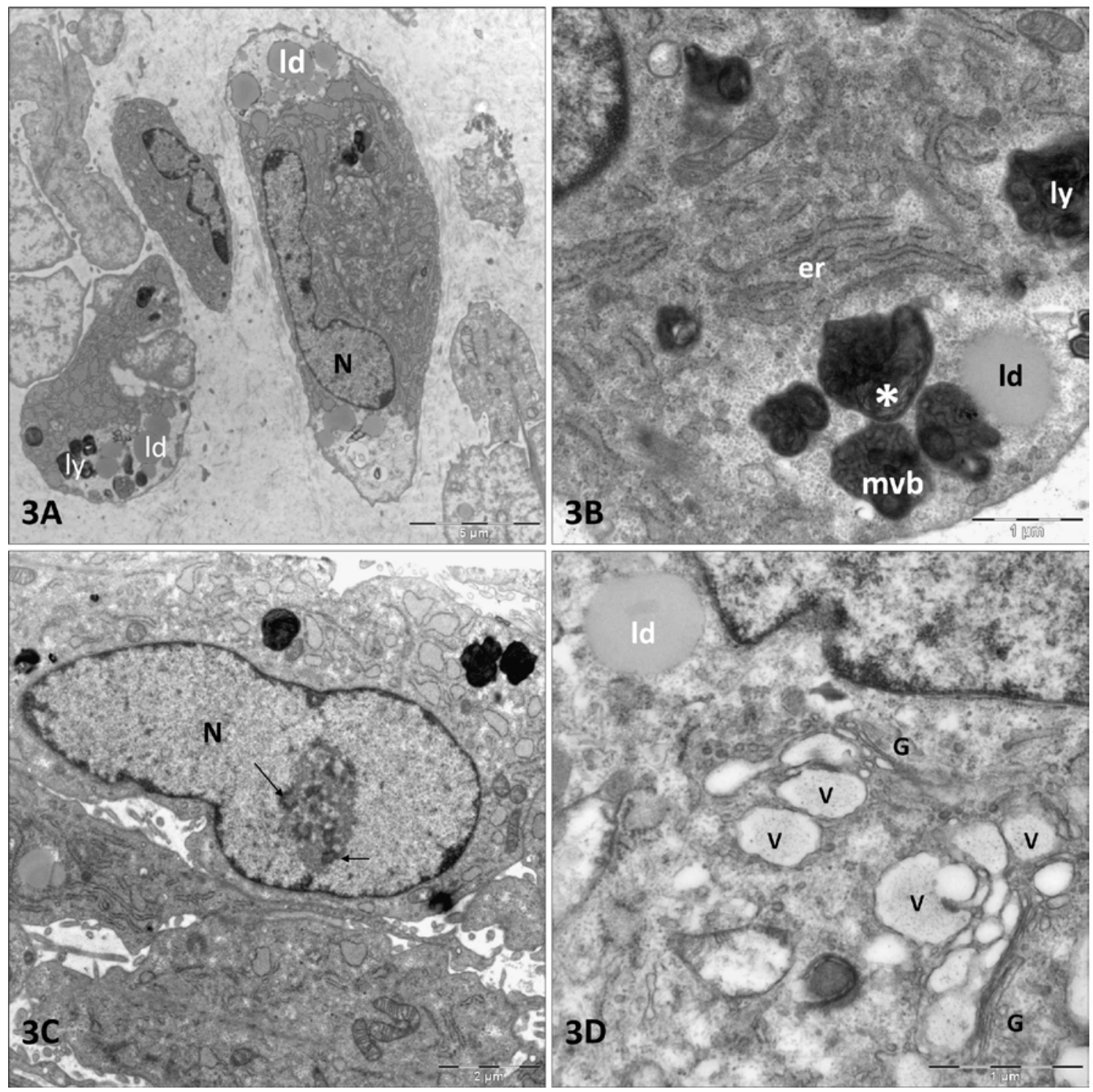

Figure 4

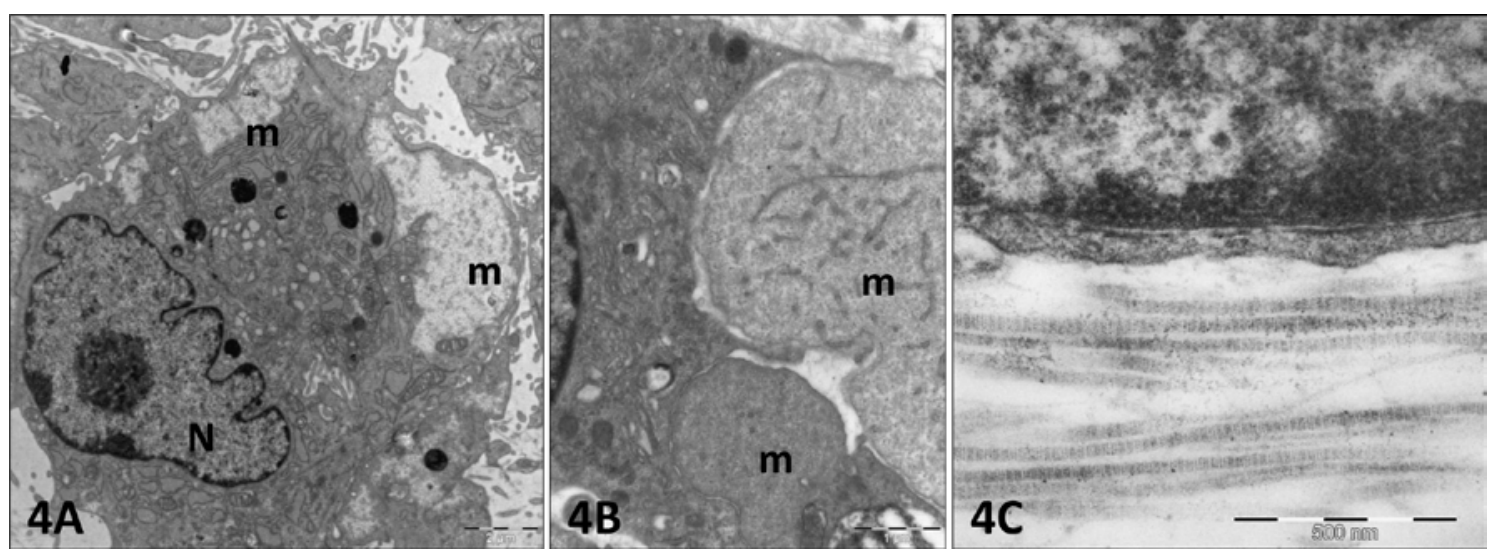


Figure 5
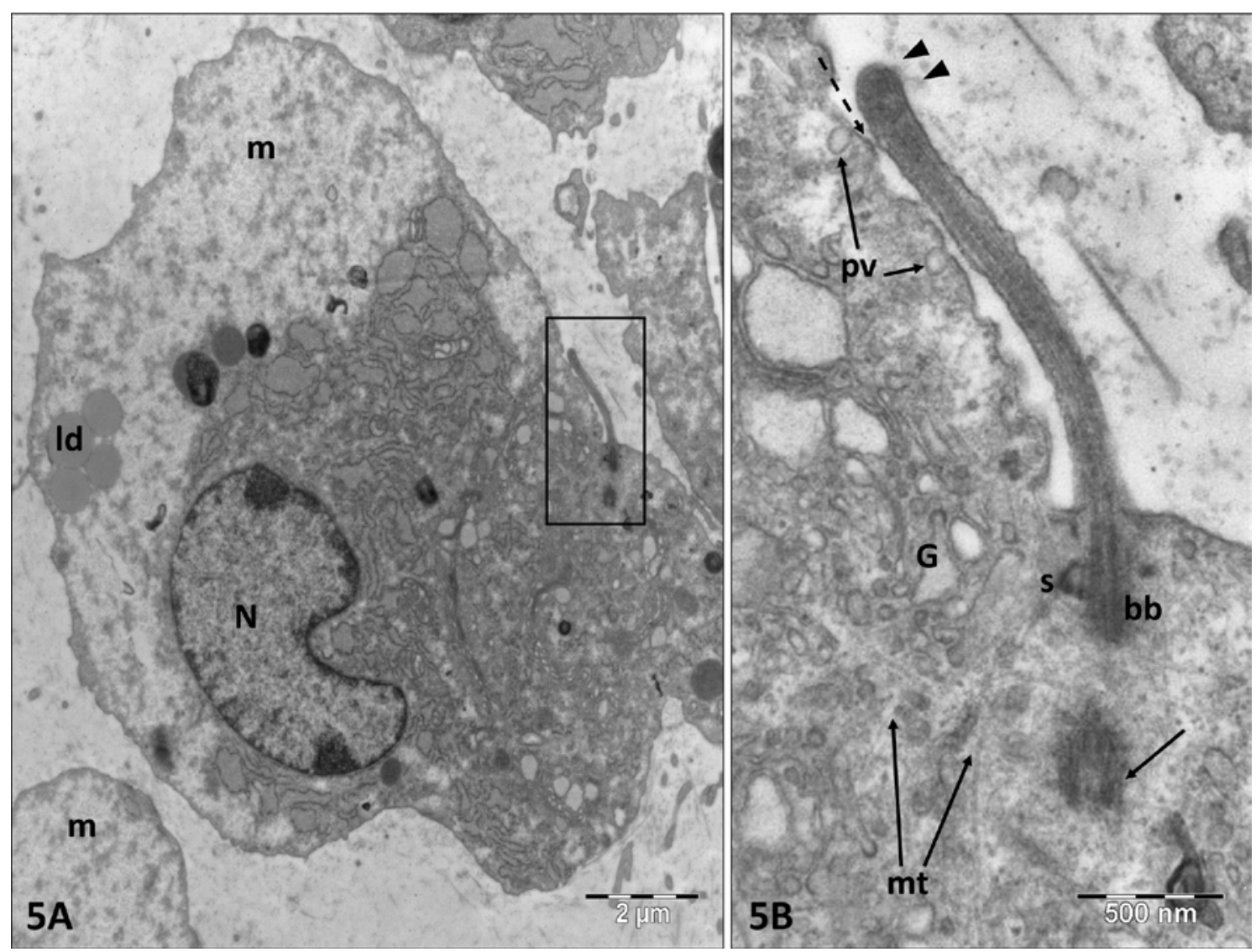